\title{
Clinical and ElectrophysiologicAspects of Guillain Barre Syndrome among Children: Experience at Referral Tertiary Care Hospital in Bangladesh
}

\author{
Bithi Debnath ${ }^{1}$, Mohammad Enayet Hussain², Nazmul Haque ${ }^{3}$, AFM Al Masum Khan ${ }^{4}$
} Md. Ferdous Mian', Md. Nahidul Islam ${ }^{6}$, Narayan Chandra Saha ${ }^{7}$, Md. Badrul Alam Md. Azharul Hoque ${ }^{9}$, Quazi Deen Mohammad ${ }^{10}$, Rajib Nayan Chowdhury ${ }^{11}$

${ }^{1}$ Assistant Professor, Department of Pediatric Neurology, National Institute of Neurosciences \& Hospital, Dhaka, Bangladesh; ${ }^{2}$ Associate Professor, Department of Neurology, National Institute of Neurosciences \& Hospital, Dhaka, Bangladesh; ${ }^{3}$ Assistant Professor, Department of Pediatric Neurology, National Institute of Neurosciences \& Hospital, Dhaka, Bangladesh; ${ }^{4}$ Medical Officer, Department of Interventional Neurology, National Institute of Neurosciences \& Hospital, Dhaka, Bangladesh; ${ }^{5}$ Assistant Professor, Department of Neurology, National Institute of Neurosciences \& Hospital, Dhaka, Bangladesh; ${ }^{6}$ Assistant Professor, Department of

Neurology, National Institute of Neurosciences \& Hospital, Dhaka, Bangladesh; ${ }^{7}$ Professor and Head, Department of Pediatric

Neurology, National Institute of Neurosciences \& Hospital, Dhaka, Bangladesh; ${ }^{8}$ Professor and Joint Director, Department of Neurology, National Institute of Neurosciences \& Hospital, Dhaka, Bangladesh; ${ }^{9}$ Professor \& Head, Department of Neurology, National Institute of Neurosciences \& Hospital, Dhaka, Bangladesh, ${ }^{10}$ Professor \&Director, Department of Neurology, National Institute of Neurosciences \& Hospital, Dhaka, Bangladesh, ${ }^{11}$ Associate Professor and Head, Department of Neurophysiology, National Institute of Neurosciences \& Hospital, Dhaka, Bangladesh;

[Received: 12 August 2019; Accepted: 20 October 2019; Published: 1 January 2019]

\begin{abstract}
Background: Guillain Barre Syndrome (GBS) is an acute polyradiculopathy which is quite common in all ages. Objective: The aim of this study was to evaluate the clinical and electrophysiologicaspects of Guillain Barre Syndrome (GBS) in children. Methodology: This cross-sectional study was carried out in the Department of Neurophysiology of National Institute of Neurosciences and Hospital, Bangladesh from July 2016 to June 2018. Patients under 18 years of age fulfilling Brighton diagnostic criteria for GBS were included in this study. These patients were evaluated by detailed history, physical examination, and electrophysiological findings. Results: A total of 82 patients of GBS were enrolled in this study. The mean age was $12.93 \pm 5.02$ years (range 1 to $<18$ years). Most of the patients were male $(64.6 \%)$ and from the middle-income group (70.73\%). About Fourty eight percent of patients had a history of preceding illness among which gastrointestinal infection $(24.3 \%)$ was the most common. Tingling and paresthesiaswas complained by $32.4 \%$ of patients as the first symptom. AMAN(61\%) was the most common GBS variant followed by AIDP(26.8\%). 9 (11\%) patients needed ICU support among them AIDP was more frequent. Conclusion: AMAN is the most common variant among children in this population by electrophysiologic testing. [Journal of National Institute of Neurosciences Bangladesh, 2019;5(2):2-7]
\end{abstract}

Keywords: Guillain Barre Syndrome; Electrophysiologic evaluations; Acute inflammatory demyelinating polyneuropathy, Acute motor axonal neuropathy; Acute motor sensory axonal neuropathy; Miller Fisher syndrome; Intensive care unit

Correspondence: Dr. BithiDebnath, Assistant Professor, Department of Pediatric Neurology, National Institute of Neurosciences \& Hospital, Sher-e-Bangla Nagar, Dhaka-1207, Bangladesh; Cell no.: +8801711236107; Email:bithidebnath@gmail.com

Conflict of interest: There is no conflict of interest relevant to this paper to disclose.

Funding agency: This research project was not funded by any group or any institution.

Contribution of authors: BD, MEH were involved in data collection, compiling and manuscript writing. Rests were involved in designing and overall supervision.

How to cite this article: Debnath B, Hussain ME, Haque MN, Khan AFMAM, Mian MF, Islam MN, Saha NC, Alam MB,Hoque MA, Mohammad QD, Chowdhury RN. Clinical and Electrophysiologic Aspects of Guillain Barre Syndrome among Children: Experience at Referral Tertiary Care Hospital in Bangladesh. J NatlInstNeurosci Bangladesh, 2019;5(1): 2-7

Copyright: (C2019. Debnath et al. Published by Journal of National Institute of Neurosciences Bangladesh. This article is published under the Creative Commons CC BY-NC License (https://creativecommons.org/licenses/by-nc/4.0/). This license permits use, distribution and reproduction in any medium, provided the original work is properly cited, and is not used for commercial purposes.

\section{Introduction}

Guillain Barre Syndrome (GBS) is an acute polyradiculopathy which affects all age groups. With the gradual eradication of poliomyelitis due to immunization, it is now the most frequent cause of acute flaccid paralysis in most countries ${ }^{1-2}$. The diagnosis of GBS is based on clinical features ${ }^{3}$, supported by features of electrophysiologic study. Electrophysiologic criteria 
have been established for the diagnosis of GBS. Specific evaluations of children have been performed but detailed large scale case-series reports of children have not $t^{4}$. The electrodiagnostic findings in these patients include acute demyelinating neuropathy, acute axonal neuropathy, or a combination of these two $0^{5-7}$.

A systematic literature review of the epidemiology of GBS has found the overall incidence of GBS to be 1.1 to $1.8 / 100000$. It is, however, lower in children at 0.34 to $1.34 / 100000^{8}$.The nonpolio incidence rate of acute flaccid paralysis(AFP) in Bangladesh is 3.25 cases per 100000 children $<15$ years of age ${ }^{9}$. A current hospital-based study shows that $25.0 \%$ of GBS patients in Bangladesh are children $<15$ years of age ${ }^{10}$.

Acute inflammatory demyelinating polyradiculoneuropathy(AIDP) is the most frequent subtype in the Western world with a primarily demyelinating pathology and various degrees of secondary axonal damage. Acute motor axonal neuropathy (AMAN) ${ }^{11}$ is the next most frequent variant and appears to be a primary axonal disorder affecting predominantly motor nerves. Axonal variants involving both sensory and motor nerves are much rarer (AMSAN) ${ }^{12}$. Most of our knowledge of Guillain Barre variants has come from studies in several western series. However, different populations around the world would have different clinical and paraclinical findings. The aim of this study was to evaluate the clinical and electrophysiologic findings of Guillain Barre Syndrome (GBS) in children.

\section{Methodology}

This cross-sectional study was carried out in the Department of Neurophysiology of National Institute of Neurosciences and Hospital, Bangladesh from July 2016 to June 2018. Suspected cases of GBS were referred to the neurophysiology lab both for diagnosis and variant identification. Patients under 18 years of age fulfilling Brighton diagnostic criteria for GBS were included in this study. All demographic, clinical, laboratory and electrophysiological data were recorded.In this hospital, patients up to the age of 12 years old are admitted to the Department of Pediatric Neurology and those $>12$ years in the Department of Neurology. For all the enrolled patients, clinical parameters including age, sex, antecedent events, interval from disease onset to admission and time from onset of symptom to nadir, muscle weakness evaluated by the Medical Research Council (MRC) scale, sensory disturbances, reflexes, cranial nerve deficits, autonomic dysfunction (e.g. tachyarrhythmia, bradyarrhythmia and abnormal sweating), pain, mechanical ventilation and treatment modality during hospitalization were collected. Where CSF was analyzed for cell count, glucose and protein concentration, data were collected. Moreover, Neurophysiological studies were done in accordance with the criteria of Hadden et al. ${ }^{12}$ Nerve conduction studies of crossed limbs (Right upper and left lower limb) were done in every patient on the day patient was referred to neurophysiology laboratory. Statistical analyses ( $p$ value, odds ratio, confidence interval) were performed using the SPSS16 for Windows program.

\section{Results}

A total of 82 patients fulfilling Brighton diagnostic criteria for GBS were enrolled in this study. The mean age was $12.93 \pm 5.02$ years (range 1 to 17 years). Most of the patients were male $(64.6 \%)$ and from the middle-income group $(70.73 \%)$. Male and female ratio was 1.82 . The majority of the patients was in the age group of 14 to 17 years. There were no patients under 1 year of age. Antecedent events were reported in $59.75 \%$ cases preceding the onset of the weakness; of which gastrointestinal infection $(29.27 \%)$ was most

Table 1: Baseline and clinical data of GBS patients

\begin{tabular}{|c|c|c|}
\hline Variables & Frequency & Percent \\
\hline \multicolumn{3}{|l|}{ Gender } \\
\hline Male & 53 & 64.6 \\
\hline Female & 29 & 35.4 \\
\hline \multicolumn{3}{|l|}{ Residence } \\
\hline Urban & 35 & 42.68 \\
\hline Rural & 47 & 57.32 \\
\hline \multicolumn{3}{|l|}{ Age Group (years) } \\
\hline - 1 to 5 Years & 8 & 9.8 \\
\hline - 6 to 9 Years & 10 & 12.2 \\
\hline - 10 to 13 Years & 23 & 28 \\
\hline - 14 to 17 Years & 41 & 50 \\
\hline \multicolumn{3}{|l|}{ Antecedent events } \\
\hline - Gastrointestinal infection & 24 & 29.27 \\
\hline - Upper respiratory infection & 14 & 17.07 \\
\hline - Fever & 10 & 12.19 \\
\hline - Vaccination & 1 & 1.22 \\
\hline - None & 33 & 40.24 \\
\hline $\begin{array}{l}\text { The time between symptom } \\
\text { onset to admission(days) }\end{array}$ & \multicolumn{2}{|c|}{$5.44 \pm 3.37$} \\
\hline Mean \pm SD Range & \multicolumn{2}{|c|}{2 to 15} \\
\hline \multicolumn{3}{|l|}{$\begin{array}{l}\text { Progression to maximum } \\
\text { paralysis from onset (day) }\end{array}$} \\
\hline Mean \pm SD & \multicolumn{2}{|c|}{$5.38 \pm 2.53$} \\
\hline Mean Range & \multicolumn{2}{|c|}{3 to 12} \\
\hline
\end{tabular}


frequent followed by respiratory tract infection (17.07\%). Meantime between symptom onset to admission and progression to maximum paralysis from the onset was $5.44 \pm 3.37$ and $5.38 \pm 2.53$ days, respectively (Table1).

Though the disease occurred sporadically throughout the year, the highest number of cases of GBS was seen in the month of April and May (13.41\% and 19.51\%). Another peak was seen in December and January (Figure 1).

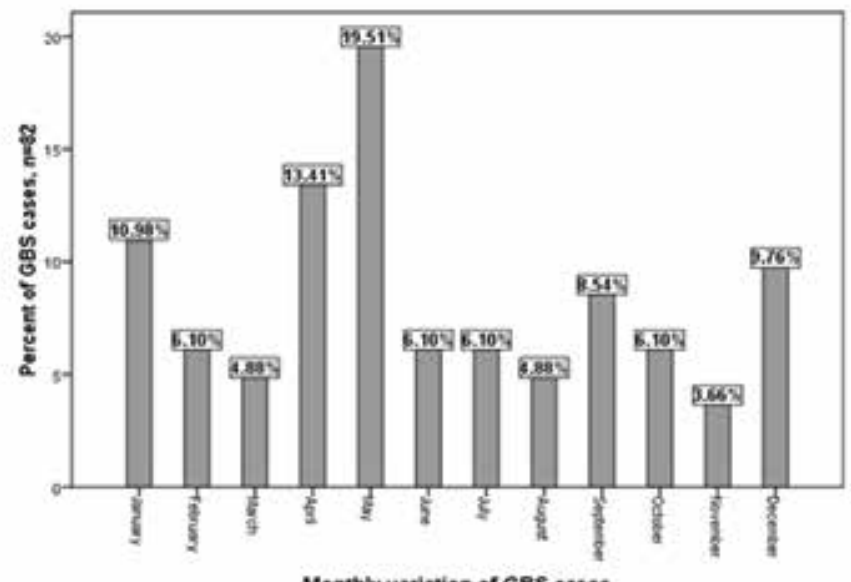

Figure I: Distribution of GBS cases according to month during the study period (July 2016-June 2018)

Tingling and paresthesiawere the first symptom in $32.4 \%$ cases followed by pain $(29.73 \%)$. Although most patients presented with weakness of both lower limbs (27.03\%),5.41\% patients had weakness initially in upper limbs (Figure2).

Multiple response analysis of symptoms found that weakness and walking difficulty were the most frequent symptoms. Facial nerve involvement occurred in $12.5 \%$ of cases, dysphagia in $6.9 \%$, and respiratory distress in $18.1 \%$ (Table 2).

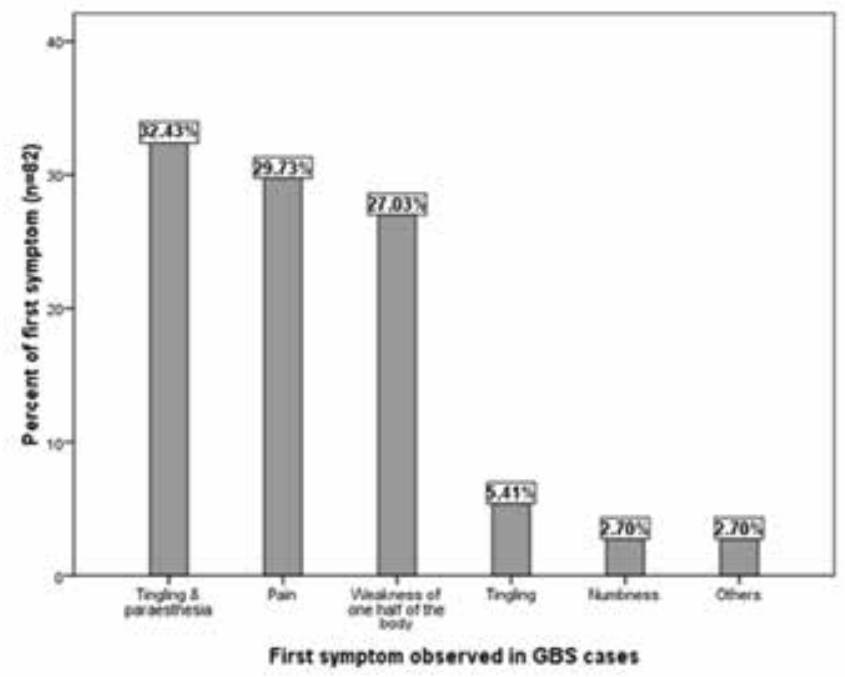

Figure II: The First Symptom Observed in Patients of GBS ( $\mathrm{n}=82$ )

Table 2: Symptoms in patients of GBS (Multiple response analysis)

\begin{tabular}{lcc}
\hline Symptoms & Frequency & Percent \\
\hline Tingling & 23 & 31.9 \\
Numbness & 7 & 9.7 \\
Paresthesia & 13 & 18.1 \\
Pain & 31 & 43.1 \\
Weakness & 68 & 94.4 \\
Walking difficulty & 53 & 73.6 \\
Deviation of the angle of mouth & 9 & 12.5 \\
Respiratory distress & 13 & 18.1 \\
Dysphasia & 5 & 6.9 \\
\hline
\end{tabular}

Mean time interval between the onset of symptoms and the time of NCS was 5.93 \pm 2.86 (range 2-14). Abnormalities in motor NCSs, F waves, and $\mathrm{H}$ reflexes were the most common electrophysiologic findings. The ulnar nerve was the most commonly involved nerve whereas conduction block was more frequent in the peroneal nerve (Table 3 ).

Table 3: Abnormalities in different NCS parameters in the studied population $(n=82)$

\begin{tabular}{lccccccccc}
\hline Nerve & $\begin{array}{c}\text { Prolonged Reduced/absent } \\
\text { DL }\end{array}$ & CMAP & Reduced & Presence of & \multicolumn{2}{c}{ Prolonged/ } & \multicolumn{2}{c}{ Prolonged } & \multicolumn{2}{c}{ Reduced/ } & Reduced & H reflex \\
& MNCV & CB & absent F wave & SDL & absent SNAP & SNCV & \\
\hline Median & $26.8 \%$ & $54.8 \%$ & $25.6 \%$ & $14.6 \%$ & $70.7 \%$ & $6.1 \%$ & $19.5 \%$ & $8.5 \%$ & Absent \\
Ulnar & $25.6 \%$ & $85.4 \%$ & $23.2 \%$ & $12.2 \%$ & $86.6 \%$ & $3.7 \%$ & $20.7 \%$ & $6.1 \%$ & 68.3 \\
Tibial & $24.4 \%$ & $70.7 \%$ & $21.9 \%$ & $8.5 \%$ & $53.7 \%$ & - & - & - & \\
Peroneal & $24.4 \%$ & $78 \%$ & $25.6 \%$ & $18.3 \%$ & - & - & - & - & Prolonged \\
Sural & - & - & - & - & - & $2.4 \%$ & $9.7 \%$ & $4.8 \%$ & 17.1 \\
\hline
\end{tabular}

DL-Distal latency, CAMP- Compound muscle action potential, MNCV- Motor nerve conduction velocity, CB-Conduction block, SDL- Sensory distal latency, SNAP- Sensory nerve action potential, SNCV- Sensory nerve conduction velocity. 
The most common electrophysiological variants of GBS were: acute motor axonal neuropathy (AMAN) in $60.98 \%$, AIDP in $26.8 \%$, acute motor and sensory axonal neuropathy (AMSAN) in $2.4 \%$, MFS in $2.4 \%$, inexcitablein $2.4 \%$ and normal in $4.8 \%$ cases (Table 4 ).

Table 4: GBS variants among studied population identified by NCS $(n=82)$

\begin{tabular}{lcc}
\hline Variants & Frequency & Percent \\
\hline AIDP & 22 & 26.83 \\
AMAN & 50 & 60.98 \\
AMSAN & 2 & 2.44 \\
GBS-MFS & 2 & 2.44 \\
Inexcitable & 2 & 2.44 \\
Normal & 4 & 4.88 \\
\hline
\end{tabular}

Lumbar puncture was done only in $34.14 \%$ cases andalbumino-cytological dissociation was found in most of the cases (89.28\%). In this study, AIDP was found to be 7.09 times more frequent in 1 to 5 years' age group $(\mathrm{p}=0.017)$. ICU support was required in 9(11\%) patients most of whom had AIDP ( $\mathrm{p}=0.03)$ (Table 5).

Table 5: Risk Estimation of AIDP among the Study Population

\begin{tabular}{lcc}
\hline Variables & Crude OR (95\% CI) & P value \\
\hline 1 to 5 years age group & $7.09(1.33-37.9)$ & $0.017^{* *}$ \\
Upper respiratory infection & $2.24(0.69-7.1)$ & 0.14 \\
Monthly variation & $1.06(0.35-3.27)$ & 0.56 \\
(December- January) & & \\
ICU support & $4.63(1.06-20.23)$ & $0.03^{* *}$ \\
\hline
\end{tabular}

*OR=Odds ratio; $\mathrm{CI}=$ Confidence interval; $* *$ statistically significant

There was a statistically significant association between gastrointestinal infection and AMAN variants $(\mathrm{p}=0.004)$ (Table 6).

Table 6: Risk Estimation of AMAN among the Study Population

\begin{tabular}{lcc}
\hline Variables & Crude OR (95\% CI) & P value \\
\hline 6 to 9 years age group & $0.95(0.25-3.67)$ & 0.06 \\
10-13 years age group & $1.68(0.60-4.69)$ & 0.23 \\
14-17 years age group & $1.23(0.50-2.99)$ & 0.41 \\
Gastrointestinal infection & $5.06(1.54-16.64)$ & $0.004^{* *}$ \\
Monthly variation & $1.13(0.44-2.93)$ & 0.49 \\
(April-May) & & \\
\hline
\end{tabular}

*OR=Odds ratio; $\mathrm{CI}=$ Confidence interval; ${ }^{* * \text { Statistically significant }}$

\section{Discussion}

In this study, 82 patients, referred for nerve conduction studies from the inpatient department to neurophysiology lab with the clinical diagnosis of GBS over a period of two years from July 2016 to June 2018, were enrolled.

This study showed a male preponderance with the sex ratio being 1.82:1 which is consistent with other studies on GBS. In thisseries, themajority of cases occurred in the 14 to 17 years' age group. With increasing age, the number of cases also increased. However, patients 1-5 years of age had a significant risk of developing AIDP. In other studies, children 1 to 4 years old were the most commonly affected age group with GBS where AIDP was predominant varient $t^{13-16}$. This is believed to be due to their relatively high susceptibility to infections in this age group and the increased susceptibility to the young myelinated peripheral nerves to demyelination ${ }^{15-16}$.

In this study, $29.3 \%$ patients had gastrointestinal infections while $17.1 \%$ patients had upper respiratory infections 1 to 4 weeks before the onset of GBS. There was a significant association between gastrointestinal infection and AMAN variants. This finding matches well with the observations of Zaheer et $\mathrm{al}^{17}$ from Pakistan that some sort of a relationship exists in the Asian countries between seasonal peaks of GBS with widespread epidemics of summer gastroenteritis and winter flu-like syndromes. In this South-Asian region, gastroenteritis outbreaks in warmer months are associated withan increasing number of GBS in the summer season. Most current epidemiological surveys show the risk of immunization triggering GBS to bevery low ${ }^{18}$. This present study was found only one patient where vaccination was a triggering factor. Although the disease occurred throughout the year in all seasons, in this study, the highest number of cases were seen in the months of April and May. Another peak was seen in the months of December and January. Islam et $\mathrm{al}^{19}$ in a study on childhood GBS from Bangladesh have reported maximum cases in the month of May and least in February.These findings are similar to this present study. In another study from Iran by Haghighi et $\mathrm{al}^{20}$ the maximum incidence of GBS was reported between the months of February to June. Lyuet $\mathrm{al}^{21}$ have reported the peak GBS incidence from March to May in a Taiwanese study. Conversely, peak clustering of GBS in the winter months has been reported from studies done primarily from the Western Hemisphere ${ }^{22-28}$.

The most common initial symptom was tingling and paresthesia. Severe radicular back pain or neuropathic pain was reported in most cases. Most patients presented initially with leg weakness while few had an onset of weakness in the arms. These findings are 
consistent with a studyby Barohn et $\mathrm{al}^{29}$. Facial nerve involvement, dysphagia and respiratory distress developed in a few cases. These percentages are lower than the study finding conducted by Ropper et $\mathrm{a}^{30}$.

When GBS is suspected, electrophysiologic studies are essential to confirm the diagnosis, identify variants and exclude its mimics. Large case series reporting electrophysiologic findings in children with GBS are few $^{4-7,31-33}$. Previous studies have shown an increase in distal latency and a decrease in nerve conduction in the children with GBS, which primarily reflects peripheral nerve demyelination ${ }^{34}$. In this study, abnormalities of motor NCS mainly low CMAP amplitude, F waves, and $\mathrm{H}$ reflex were more common than the abnormalities of sensory NCS. A study in Northeast China found that motor nerve involvement was more common in children than that in adults with AMAN or AIDP, while in children with AIDP, sensory nerve involvement in the lower limbs was less common than that in adults ${ }^{35}$.

In this study, AMAN was the most common variant followed by AIDP. In other studies, the incidence of the demyelinating type of GBS was $69.0 \%$ in $\mathrm{Japan}^{36}$, $70.0 \%$ in Argentina ${ }^{37}, 65.0 \%$ in Turkey ${ }^{38}, 69.0 \%$ in Pakistan $^{39}, 35.0 \%$ in $\mathrm{China}^{40}$, and $90.0 \%$ in North America $^{41}$. In AMAN, CMAP amplitudes are significantly reduced in the first few days and then in severe cases become absent ${ }^{42}$. In AMSAN the sensory potentials are reduced in amplitude and often absent ${ }^{43}$. The absence of H-reflexes may be the only abnormality in $75 \%$ of MFS and BBE cases $^{44}$. The percentage of cases with the demyelinating type in our study $(26.83 \%)$ was lower than that in western countries. These findings suggest that the incidence of the demyelinating type of GBS varies considerably among countries. It may be due to a different genetic background and environmental exposures.

CSF examination was performed in one-third of cases because most of the patients were referred to the lab before lumbar puncture. At our institution, lumbar punctures are typically performed ${ }^{7}$ days after onset of symptoms. In this study, it has been found a statistically significant association between AIDP and patients requiring ICU support.

\section{Conclusion}

GBS affects males more than females. The number of the patient increases with increasing age. Most cases are reported in the months of April-May and December-January. AMAN is the most common variants. However, AIDP is more frequent in the younger age group. The gastrointestinal infection has a significant association with AMAN. Patients having AIDP have more chance to develop respiratory failure and required ICU support. Although this present study has been conducted in a referral neurology hospital in Bangladesh, there are limitations of this study. Among these limitation small sample size is an important issue. Randomization was not done to avoid selection bias. This present study is performed in a single medical centre which does not reflect the whole country scenarios.

\section{References}

1. Ropper AH. The Guillain囚Barre syndrome.N Engl J Med. 1992;326(17):1130区6

2. Hahn AF. Guillain囚Barre syndrome. Lancet.1998; 352(9128): $635 \square 41$

3. Asbury AK, Cornblath DR. Assessment of current Diagnostic Criteria for Guillain囚Barre syndrome. Ann Neurol. 1990;27(suppl): S21区4

4. Bradshaw DY, Jones HR Jr. Guillain囚Barrésyndrome in children: clinical course, electrodiagnosis, and prognosis. MuscleNerve. 1992;15(4):500冈6

5. Delanoe C, Sebire G, Landrieu P, etal.Acute inflammatory demyelinating polyradiculopathy in children: clinical and electrodiagnostic studies. Ann Neurol.1998;44(3):350冈6

6. Hung PL, Chang WN, Huang LT, et al. Aclinical and electrophysiologic survey ofchildhood Guillain冈Barre syndrome.PediatrNeurol 2004;30(2):86ه91

7. Jones HR. Guillain囚Barre syndrome: perspectives with infants and children.SeminPediatr Neurol. 2000;7(2):91囚102

8. McGrogan A, Madle GC, Seaman HE, de Vries CS. The epidemiology of Guillain-Barre syndrome worldwide. A systematic literature review. Neuroepidemiology 2009; 32(2):150-163

9. World Health Organization. EPI surveillance bulletin, vol.11,no.6, 2008

10. Islam Z, Jacobs BC, van Belkum A, Mohammad QD, Islam MB, Herbrink P, Endemic axonal variant of Guillain-Barre syndrome frequently associated with Campylobacter infections in Bangladesh. Neurology.2010;74:581-7

11. Griffin JW, Li CY, Ho TW, Xue P, Macko C, Gao CY, Yang C, Tian M, Mishu B, Cornblath DR, McKhann GM. Guillain-Barré syndrome in northern China: the spectrum of neuropathological changes in clinically defined cases. Brain. 1995;118(3):577-95

12. Hadden RDM, Cornblath DR, Hughes RAC, Zielasek J, Hartung HP, Toyka K, et al: Electrophysiological classification of Guillain-Barré Syndrome: clinical associations and outcome. Ann Neurol 1998, 44:780-788

13. Landaverde JM, Danovaro-Holliday MC, Trumbo SP, Pacis-Tirso CL, Ruiz-Matus C: Guillain-Barre syndrome in children aged $<15$ years in Latin America and the Caribbean: baseline rates in the context of the influenza A (H1N1) pandemic. J Infect Dis 2010, 201(5):746-750

14. Molinero MR, Varon D, Holden KR, Sladky JT, Molina IB, Cleaves F: Epidemiology of childhood Guillain-Barre syndrome as a cause of acute flaccid paralysis in Honduras: 1989-1999. J Child Neurol 2003, 18(11):741-747

15. Koul R, Al-Futaisi A, Chacko A, Fazalullah M, Nabhani SA, Al-Awaidy S, Al-Busaidy S, Al-Mahrooqi S: Clinical characteristics of childhood Guillain-barre syndrome. Oman Med 
J 2008, 23(3):158-161

16. Rantala H, Cherry JD, Shields WD, Uhari M: Epidemiology of Guillain-Barre syndrome in children: relationship of oral polio vaccine administration to occurrence. J Pediatr 1994, 124(2):220-223

17. Zaheer M, Naeem M, Nasrullah M. Seasonal variation and sex distribution in patients with Guillain-Barré syndrome. Pak J NeurolSci 2008;3:6-8

18. Bardage C, Persson I, Örtqvist $\AA$, Bergman U, Ludvigsson JF, Granath F. Neurological and autoimmune disorders after vaccination against pandemic influenza A (H1N1) with a monovalent adjuvanted vaccine: population based cohort study in Stockholm, Sweden. BMJ. 2011 Oct 12;343:d5956

19. Islam Z, Jacobs BC, Islam MB, Mohammad QD, Diorditsa S, Endtz HP. High incidence of Guillain-Barre syndrome in children, Bangladesh. Emerging infectious diseases. 2011;17(7):1317

20. Haghighi AB, Banihashemi MA, Zamiri N, Sabayan B, Heydari ST, Safari A, Lankarani KB, Chang YT, Chang CC, Lin HS, Huang CW. Seasonal variation of Guillain-Barre syndrome admission in a large tertiary referral center in southern Iran: a 10-year analysis. ActaNeurologica Taiwanica. 2012;21(2):60-321

21. Lyu RK, Tang LM, Cheng SY, Hsu WC, Chen ST. Guillain-Barré syndrome in Taiwan: a clinical study of 167 patients. Journal of Neurology, Neurosurgery \& Psychiatry. 1997;63(4):494-500

22. Van Koningsveld R, Rico R, Gerstenbluth I, Schmitz PI, Ang CW, Merkies IS, Jacobs BC, Halabi Y, Endtz HP, van der Meché FG, Van Doorn PA. Gastroenteritis-associated Guillain-Barre syndrome on the Caribbean island Curacao. Neurology. 2001;56(11):1467-72

23. Radhakrishnan K, El『Mangoush MA, Gerry SE. Descriptive epidemiology of selected neuromuscular disorders in Benghazi, Libya. ActaneurologicaScandinavica. 1987;75(2):95-100

24. Winner SJ, Evans JG. Age-specific incidence of Guillain-Barré syndrome in Oxford shire. QJM: An International Journal of Medicine. 1990;77(3):1297-304

25. Congia S, Melis M, Carboni MA. Epidemiologic and clinical features of the Guillain-Barre'syndrome in Sardinia in the 1961-1980 period. Actaneurologica. 1989;11(1):15-20

26. Larsen JP, Kvale G, Nyland H. Epidemiology of the Guillain囚Barré syndrome in the county of Hordaland, Western Norway. Actaneurologicascandinavica. 1985;71(1):43-7

27. SivadonTV, Orlikowski D, Rozenberg F, Caudie C, Sharshar T, Lebon P, Gaillard JL. Guillain-Barré Syndrome, Greater Paris Area. Emerging Infectious Diseases, 2006;12(6):990-993

28. Louie M, Gilchrist JM, Woodard C. Guillain-Barre syndrome: a 5-year Rhode Island hospital experience. Rhode Island Medicine. 1994;77(5):135
29. Barohn RJ, Saperstein DS. Guillain-Barre syndrome and chronic inflammatory demyelinating polyneuropathy. Semin Neurol. 1998;18(1):49-61

30. RopperAH, Wijdicks EFM, Truax BT. Guillain-Barre Syndrome, Contemporary Neurology Series. Davis, FA., editor. Vol. 34. Philadelphia, PA: 1991. Comp

31. Amin R, Akbari A, Al Yasin S, et al. Guillain区Barre syndrome: A 20囚year study on pediatrics. JFeiz. 1383; 18(32) $63 \rrbracket 69$

32. Ashrafzade F, Aria Manesh A. Outcome of Guillain囚Barre syndrome in children. Iranian J Pediatr. 2005;15(4):309ه14

33. Barzegar M, DavariFarid S, Dastgiri S, et al. Childhood Guillain冈Barre syndrome in Iran's East Azerbaijan Province: 2001凶2005. Iran J Child Neurol. 2008;2(4):25凶31

34. Ryan MM. Guillain-Barre syndrome in childhood. J Paediatr Child Health 2005;41:237e41

35. Ye YQ, Wang KR, Sun L, Wang Z. Clinical and electrophysiologic features of childhood Guillain-Barré syndrome in Northeast China. Journal of the Formosan Medical Association. 2014;113(9):634-9

36. Nagasawa K, Kowabara S, Misawa S, et al. Electrophysiological subtypes and prognosis of childhood Guillain】 Barre syndrome in Japan. Muscle Nerve. 2006; 33(6):766区70

37. Paradise G, Trpoli J, Galicchio S, et al.Clinical and electrophysiological predictors of respiratory failure Guillain囚Barre syndrome: a reappraisal. Ann Neurol. 1999;46(5):701ه5

38. Tekgul H, Serdaroglu G, Tutuncuoglu S. Outcome of axonal and demyelinating forms in Guillain囚Barre syndrome in children. Pediatric Neurol. 2003;28(4):295区9

39. Shafqat S, Khealani BA, Awan F, et al.Guillain囚Barre syndrome in Pakistan: similarity of demyelinating and axonal variants.Eur J Neurol. 2006;13(5):662区5

40. Mckhann GM, Gornblath DR, Griffin JW, et al. Acute motor axonal GBS in China. Ann Neurol. 1993;33(4):333凶42

41. Brown WF, Feasby TE, Hahn AF. Electrophysiological changes in the acute axonal form of GBS. Muscle Nerve. 1993;16(2):200冈5

42. Albers JW, Kelly JJ Jr. Acquired inflammatory demyelinating polyneuropathies: clinical and electrodiagnostic features. Muscle Nerve. 1989; 12(6):435-451

43. Griffin JW, Li CY, Ho TW, et al. Pathology of the motor-sensory axonal Guillain-Barre syndrome. Ann Neurol. 1996; 39(1):17-28

44. Ito M, Kuwabara S, Odaka M, et al. Bickerstaff's brainstem encephalitis and Fisher syndrome forma continuous spectrum: clinical analysis of 581 cases. J Neurol 2008;255(5):674-682 